Article

\title{
Research on Model-Based Fault Diagnosis for a Gas Turbine Based on Transient Performance
}

\author{
Detang Zeng ${ }^{1,2, *}$, Dengji Zhou ${ }^{3,4, *}$, Chunqing Tan ${ }^{1,2}$ and Baoyang Jiang ${ }^{4}$ \\ 1 Institute of Engineering Thermophysics, Chinese Academy of Science, Beijing 100190, China; tan@iet.cn \\ 2 University of Chinese Academy of Sciences, Beijing 100049, China \\ 3 The Key Laboratory of Power Machinery and Engineering of Education Ministry, \\ Shanghai Jiao Tong University, Shanghai 200240, China \\ 4 Department of Mechanical Engineering, University of Michigan, Ann Arbor, MI 48109, USA; \\ byjiang@umich.edu \\ * Correspondence: zengdetang@iet.cn (D.Z.); zhoudj@sjtu.edu.cn (D.Z.)
}

Received: 7 November 2017; Accepted: 26 December 2017; Published: 22 January 2018

\begin{abstract}
It is essential to monitor and to diagnose faults in rotating machinery with a high thrust-weight ratio and complex structure for a variety of industrial applications, for which reliable signal measurements are required. However, the measured values consist of the true values of the parameters, the inertia of measurements, random errors and systematic errors. Such signals cannot reflect the true performance state and the health state of rotating machinery accurately. High-quality, steady-state measurements are necessary for most current diagnostic methods. Unfortunately, it is hard to obtain these kinds of measurements for most rotating machinery. Diagnosis based on transient performance is a useful tool that can potentially solve this problem. A model-based fault diagnosis method for gas turbines based on transient performance is proposed in this paper. The fault diagnosis consists of a dynamic simulation model, a diagnostic scheme, and an optimization algorithm. A high-accuracy, nonlinear, dynamic gas turbine model using a modular modeling method is presented that involves thermophysical properties, a component characteristic chart, and system inertial. The startup process is simulated using this model. The consistency between the simulation results and the field operation data shows the validity of the model and the advantages of transient accumulated deviation. In addition, a diagnostic scheme is designed to fulfill this process. Finally, cuckoo search is selected to solve the optimization problem in fault diagnosis. Comparative diagnostic results for a gas turbine before and after washing indicate the improved effectiveness and accuracy of the proposed method of using data from transient processes, compared with traditional methods using data from the steady state.
\end{abstract}

Keywords: fault diagnosis; gas turbine; transient performance; cuckoo search; modeling and simulation; deterioration

\section{Introduction}

With the deepening of the industrialization process, the revolution of industry 4.0 is emerging in many industry areas [1]. A variety of intelligent equipment and intelligent equipment management technologies have been created, so as to redefine the interaction between humans and machines [2]. With the increased complexity of equipment, fault diagnosis has become a key technology to ensure the safety and efficiency of the production process [3]. Smart fault diagnostic technologies will be essential in the age of industry 4.0. With the development of sensing and information technology, massive multi-source data can be obtained automatically from equipment, which will become the foundation of developing advanced fault diagnosis methods [4]. 
Gas turbines are widely used in the defense and energy industry. It is essential to perform fault diagnosis on a regular basis to maintain the reliability of gas turbine. However, fault diagnosis is generally a challenging task due to the structural complexity, which involves various fault modes [5]. In traditional diagnostic processes [6,7], measurement data represent the steady-state values, while the trending patterns in the transient phase are neglected. However, it is hard to determine steady-state values in the transient phase. For example, the time for military aircrafts fighting in unsteady conditions, deviating from steady states, accounts for $70 \%$ of the total fight time [8]. It is not feasible to obtain the steady-state data for a military aircraft. Additionally, the effects appear to be remarkable in transient processes compared to the steady-state condition for some kinds of fault modes $[9,10]$. Compared with the study of fault diagnosis with steady-state data, this lacks the study of fault diagnosis with transient process data. Therefore, the objective of this thesis is to study the fault diagnosis of gas turbines based on transient process data.

Many gas turbine performance-analysis-based diagnostic technologies have been developed since Urban [11] introduced the first gas path analysis method in 1967. Gas turbine engine fault diagnosis during transient processes was first analyzed by Merrington [9]. Li developed a non-linear-model-based diagnostic method, combined with a genetic algorithm, and applied it to a model gas turbine engine to diagnose engine faults by using the accumulated deviation obtained from transient measuring data [8]. Naderi proposed a data-driven fault diagnosis and estimation scheme. Fault detection, isolation and, estimations filters was developed using system Input/Output (I/O) data in operation [12]. Meher-Homji [13] provided an overview of the use of both performance and mechanical transient analysis as a means to detect gas turbine problems, to express the importance of transient analysis. Henry [14] utilized engine data acquired during takeoff to trend the performance of a modern turbofan engine. Analytical redundancy methods have been applied to gas turbine engine transient data with a view to extracting the desired fault information [15]. Simani and Fantuzzi presented a model-based procedure exploiting analytical redundancy for the detection and isolation of faults on a gas turbine process, which integrated linear model identification and output estimation [16]. The system was used in a single-shaft industrial gas turbine plant to experimentally verify the robustness of the solution obtained [17]. Lu proposed a data hierarchical fusion method, using improved, weighted Dempster-Shaffer evidence theory, to integrate data-driven and physics-based models for the gas-path fault diagnosis of engines [18].

Dynamic, process-based gas turbine fault diagnosis requires special parameters, which can describe the dynamic process of gas turbines. Due to the accumulative effects of the transient process, it will be more sensitive to choosing transient process data than steady-state data for fault diagnosis. However, current research results cannot support the fault diagnostic technology for a gas turbine based on transient process data. The following issues still remain unsolved:

- The accuracy of the algorithm should be increased;

- The diagnostic result based on steady-state data and dynamic data should be compared;

- The diagnostic method based on transient process data should be used to analyze field data.

In this paper, a novel gas-path fault diagnostic model is proposed, by engine transient performance analysis and a system dynamic model. Similar to the conventional gas-path fault diagnostic method, the proposed method has the same basic idea that a surrogate model stands for the real engine under different working conditions and health conditions. However, due to the change of input parameters from steady-state to transient process, the three key parts of the diagnostic model, which are calculation flowchart, simulation model, and algorithm, should be modified. Integrated deviations between measurements and simulation results are chosen as the fitness function in the diagnostic problem. Then this problem will be solved by the proposed calculation flowchart and heuristic algorithm. 


\section{Methodology}

To promote diagnosis based on the transient process data from theoretical study to commercial application, a novel diagnostic method based on a dynamic simulation model and Cuckoo search algorithm is proposed. A comparative study to steady-state analysis and application to analyze field data are conducted based on this novel method.

\subsection{Modeling of Gas Turbine}

The dynamic system of a gas turbine plant consists of working fluid and rotary parts. The system behavior can be derived by conservation laws and the equations of motion [19]. To analyze the dynamic characteristics of a gas turbine, unsteady three-dimensional calculations can be used. However, applying the unsteady three-dimensional simulation requires vast computational resources. It has been proved that one-dimensional simulation gives sufficiently accurate results [20]. In this study, the modular modeling method is applied to build the model. A two-shaft industrial gas turbine, which consists of one compressor, one combustor, one high pressure turbine, and one power turbine, is cited as an example for gas turbine modelling and fault diagnosis, as shown in Figure 1.

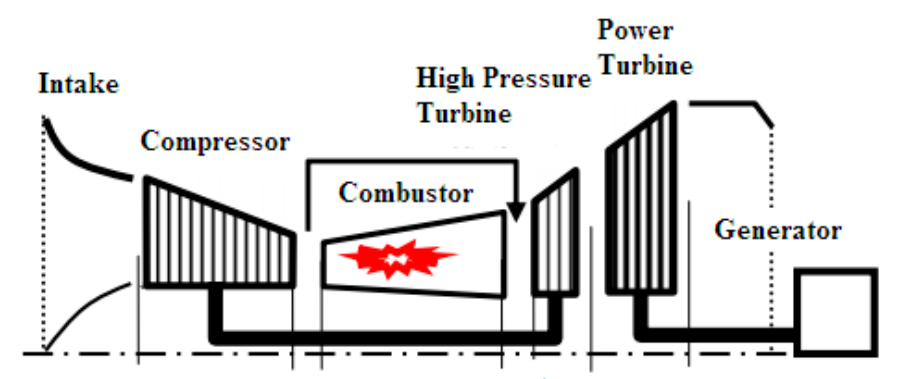

Figure 1. Gas turbine configuration of this case study.

Based on the principles of the modular modeling method, the entire plant is divided into four parts: compressor, combustor, turbine (high pressure turbine and power turbine) and rotating shaft. The input and output parameters of each module need to be defined. The modeling flowchart and modular inputs and outputs are shown in Figure 2.

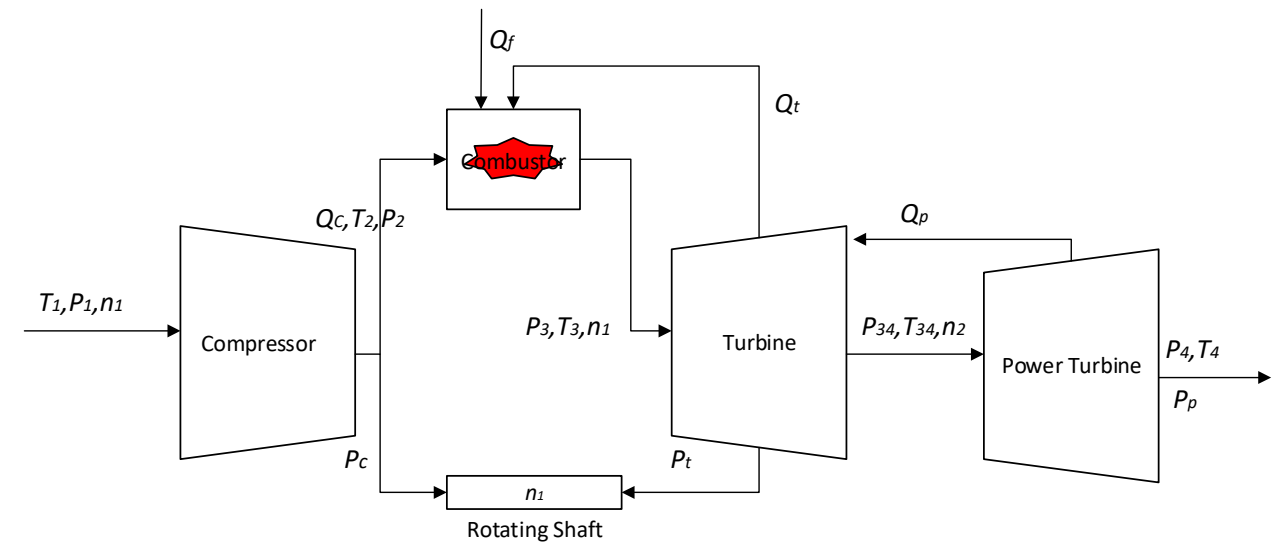

Figure 2. Modeling flowchart based on the modular modelling method for gas turbine.

Compressor and Turbine. The compressor and two turbines (high pressure turbine and power turbine) are modelled using the characteristic map that describes the correlation between pressure ratio, mass flow rate, rational speed, and efficiency. For example, compressor speed and isentropic efficiency can be determined using the characteristic map. Since the design pressure ratio of the compressor 
is known, and the mass flow rate of the air is determined from the plant operation requirement, mainly referring to power output, the compressor speed and isentropic efficiency can be read off the characteristic map.

The following lists their performances:

$$
\left(\frac{Q \sqrt{T_{i n}}}{p_{\text {in }}}, \eta\right)=f\left(\pi, n / \sqrt{T_{i n}}\right)
$$

where $\pi, n$ and $\eta$ stand for pressure ratio, rotational speed and component efficiency, and $T_{\text {in }}$ is the inlet temperature. From steady-state characteristics map generated by the field operating data [21], compressor mass flow $G_{c}$ and component efficiency $\eta$ can be calculated by Equation (1), which can be used to calculate the power required and the temperature of the discharge air.

$$
\begin{gathered}
T_{2}=\left(1+\frac{\pi^{\frac{R}{c_{p}}}-1}{\eta_{c}}\right) T_{1} \\
P_{\mathrm{c}}=G_{c} C_{p}\left(T_{2}-T_{1}\right)
\end{gathered}
$$

where $C_{p}$ is the heat capacity and $R$ is the gas constant.

The degradation of gas path components can be mathematically determined by scaled component maps. It is assumed that the degraded maps of the compressor, combustor, and turbine are down-scaled versions of the corresponding original maps, due to the fact that the geometries do not change significantly. More details on the definitions of the degradation parameters of gas turbine components can be found in reference [22,23].

Combustor. The combustor model involves the prediction of the dynamic response of pressure and temperature inside the combustor. The pressure is determined by the combustor model, while the flow rate is determined by the compressor and turbine model using the characteristics maps. Therefore, the state equation of pressure can be written as:

$$
\frac{d p}{d t}=\frac{R_{g} T_{g}}{V}\left(G_{f}+G_{c}-G_{t}\right)
$$

where the subscripts $f, c$ and $t$ stand for the fuel, compressor and turbine, respectively. $V$ is the volume of the combustor, $t$ is the time.

The turbine inlet temperature is the most important parameter for the gas turbine, which is also calculated in the combustor model. The state equation of the turbine inlet temperature can be written as follows:

$$
\frac{d T_{g}}{d t}=\frac{G_{f}\left(h_{f}+H V\right)+G_{c} h_{c}-G_{t} h_{t}-\left(h_{t}-R_{t} T_{3}\right)\left(G_{f}+G_{c}-G_{t}\right)}{\rho_{g} V c_{p, g}}
$$

where $H V$ stands for the heating value of the fuel, $h$ is the enthalpy, $c_{p, g}$ is heat capacity, and $\rho_{g}$ is the gas density in the combustor.

The turbine inlet pressure and temperature are both calculated through the state equations. The results are sent to the compressor and turbine model to obtain the pressure ratio for characteristics maps and to calculate the output power.

Rotating Shaft. A rotor is used to connect the compressor and load to the turbine. The mode is described by the following equation.

$$
\frac{d n}{d t}=\frac{900}{n I \pi^{2}}\left(P_{t}-P_{c}\right)
$$

where $I$ is the moment of inertia, $P_{t}$ is input power from turbine, $n$ is the rotational speed, and $P_{c}$ is the output power to drive the compressor. 
The fuel flow rate is calculated by a proportional-integral-derivative (PID) controller. The input of this controller is the deviation between the set rotational speed and the measuring rotational speed. After parameter tuning of the PID controller, this dynamic model can simulate the measurement parameters of this gas turbine, setting the power condition and ambient condition. The Block diagram for the speed control is shown in Figure 3.

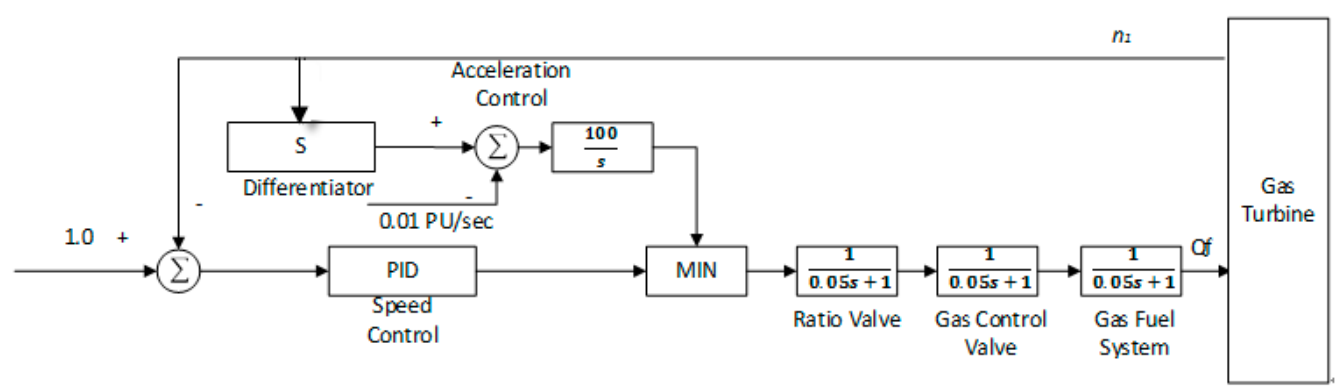

Figure 3. Block diagram for the speed control.

\subsection{Cuckoo Search Algorithm}

Cuckoo search (CS) was put forward on the basis of swarm intelligence technology by British scholar X.S. Yang and S. Deb in 2009 [24]. A CS algorithm simulates the brood parasitism habit of certain species of cuckoo to solve the optimization problem effectively. The structure of a CS algorithm is simple. It has a few control parameters and a strong ability to jump out of local extremum. It shows that in many cases, a CS algorithm shows better performance compared to a genetic algorithm (GA), artificial bee colony (ABC) algorithm, particle swarm optimization (PSO) algorithm and some other typical swarm intelligence algorithm $[25,26]$. In this paper, the CS algorithm was chosen to solve this problem, as it features high computational efficiency and accurate optimization results.

In nature, the way that cuckoos look for a suitable location of bird's nests for their own eggs is random. In order to simulate the way that cuckoos find a nest, it is necessary to set the following three ideal states:

1. A cuckoo lays one egg at a time, and selects a bird's nest to hatch it randomly;

2. In a randomly selected group of bird's nests, the best bird's nest will be retained to the next generation.

3. The number $\mathrm{n}$ of available bird's nests is fixed and the probability that an owner of a bird's nest can find an exotic birds' eggs is $\mathrm{Pa} \in[0,1]$. Based on the three ideal states, the updating formula of path and location is as follows, when the cuckoo finds a nest:

$$
X(t+1)_{i}=X(t)_{i}+\alpha \times L(\lambda), i=1,2, \cdots, n
$$

where $X(t)_{i}$ is the next location number in the cuckoo generation $t, \alpha$ represents the step control variable and $L(\lambda)$ represents the Levy random search path. Levy flight is a random movement process, the step of its flight distance obeys Levy distribution. The following formula is used to produce a Levy random number:

$$
L(\lambda)=\frac{\phi \times u}{|v|^{\frac{1}{\lambda}}}(1<\lambda<3)
$$


$u$ and $v$ obey standard normal distribution and $\lambda$ is the distribution factor, In this paper, it equals 1.5 [27]. The formula of $\varphi$ is as follows:

$$
\phi=\left\{\frac{(1+\lambda) \times \sin \left(\pi \times \frac{\lambda}{2}\right)}{\left[\left(\frac{1+\lambda}{2}\right) \times \lambda \times 2^{\frac{\lambda-1}{2}}\right]}\right\}^{\frac{1}{\lambda}}
$$

\subsection{Diagnostic System}

The diagnostic scheme was designed as in Figure 4. The input of the real gas turbine is the working condition, and the input of the simulation model is the working condition and health condition represented by the health parameters. The health condition consists of two parts, the degradation of component working ability and inertial coefficients. A detailed description of the degradation is shown in reference [23].

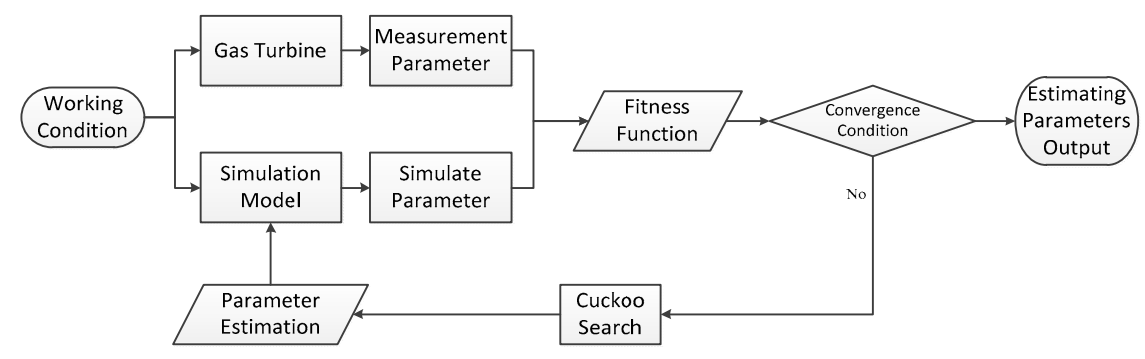

Figure 4. Scheme of fault diagnosis based on transient process measuring data.

The diagnostic process can be divided into three steps.

\section{Model simulation}

At the beginning of the calculation, we set the gas turbine faults in the gas turbine and obtained the measurable parameters after the operation of the gas turbine. By inputting the same input parameters as the measurable parameters of the fault model and inserting the health initial values diagnosed by the calculation model, the measurable parameters of the fault model can be estimated through the calculation model.

\section{Objective function calculation}

The estimated parameters given in the initial calculation are generally incorrect, therefore the deviation exists between the model and the measurable parameters in the actual gas turbine. The deviation can be determined by the objective function in a certain calculation way. The object function of this paper is defined as:

$$
f_{o b j}=\int_{t=t_{i}}^{t_{j}}\left|Z_{t}-\overline{Z_{t}}\right|
$$

3. Optimization of the estimation parameters

If the value of the objective function is small, the estimate can recognize and isolate the fault to achieve the goal of the fault diagnosis. However, when the deviation does not achieve the desired accuracy, the estimated initial value needs to be corrected through the optimization algorithm to return to the first process calculation. Such a process takes place recursively until the objective function reaches an acceptable accuracy. 


\section{Case Study}

A single spool and free power turbine industrial gas turbine is cited as an example for fault diagnosis with transient data. The basic performance parameters are shown as in Table 1.

Table 1. Base load parameters of gas turbine.

\begin{tabular}{cc}
\hline Parameter & Value \\
\hline Pressure ratio & 24.1 \\
Exhaust mass flow & $84.31 \mathrm{~kg} / \mathrm{s}$ \\
Power output & $31.4 \mathrm{MW}$ \\
Efficiency of compressor & $85 \%$ \\
\hline
\end{tabular}

\subsection{Overall Performance Test Rig}

An overall performance test rig was established to acquire transient process measuring data, see Figure 5. The data for the instrument and control system of the gas turbine, through the isolated safety barrier, is sent to the signal acquisition board, where data acquisition, data pre-processing, A-D signal conversion and data output are being completed. The calculative process is finished in the portable decay controller of the board. The processed digital signal will be published to the level I network through wireless access point (WAP) or access point (AP) web. The data management system of the portable condition monitoring system is in charge of data transformation and transmission from the level I network to level II. The interface management system of the remote data center, obtains data from the internet, sends data to main database via the level III network (remote data center local area network (LAN)) according to the defined interface rules, and stores the test data chronically. The remote data management system is mainly responsible for human-computer interactions for a remote data center, with a level III network and interface management server.

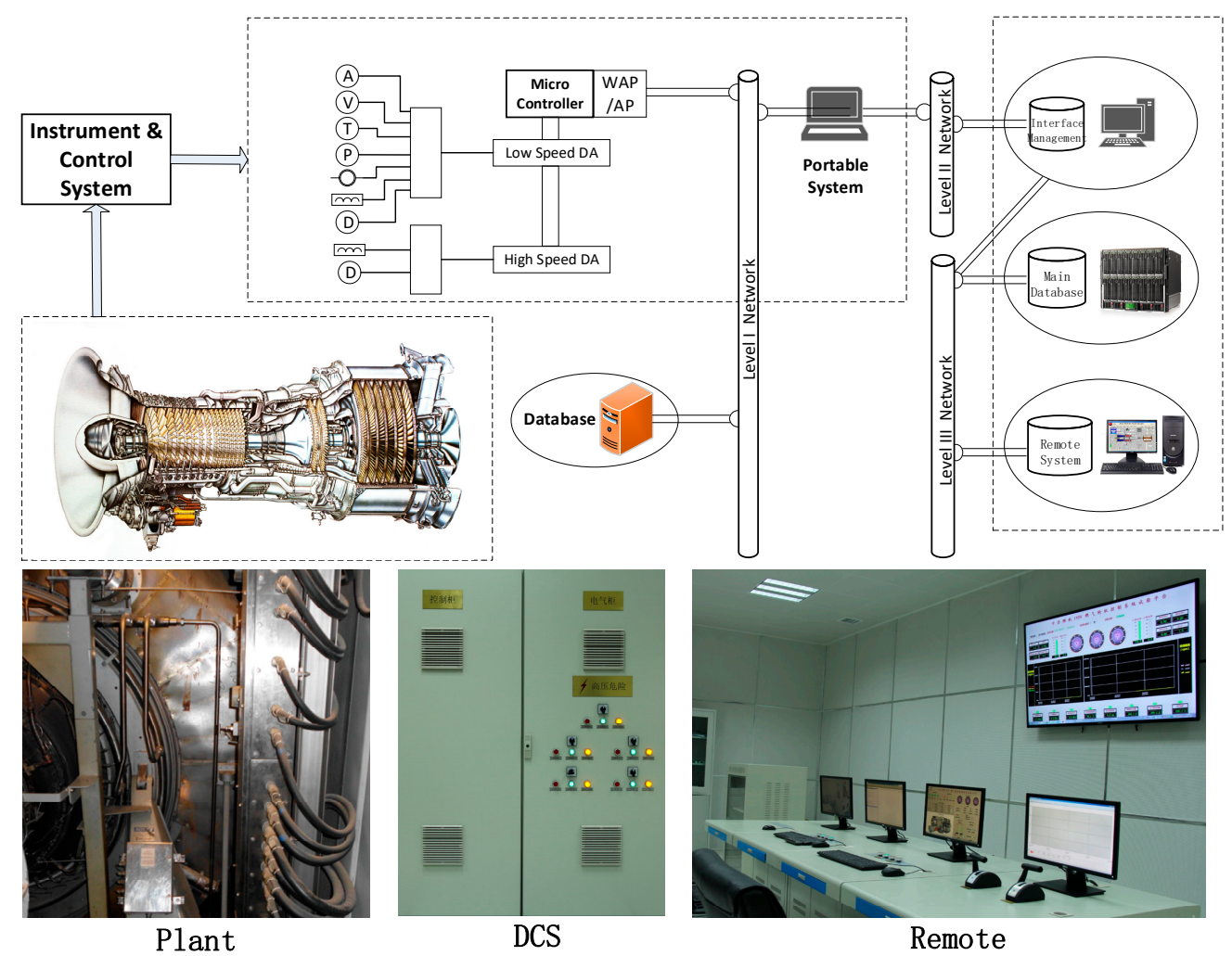

Figure 5. Gas turbine overall performance test rig. 
The data for the model validation and the case study is acquired from the instrument and control system based on the overall performance test rig. However, this is sometimes forbidden by users considering operation safety. Thus another channel is designed for data acquisition. The portable data management system is linked to the plant database via a level I network directly to get the historical data for this selection. The measuring parameters and performance parameters related to this case are listed in Table 2.

Table 2. Parameter list for this case.

\begin{tabular}{cc}
\hline Measurement Parameter & Symbol \\
\hline Rotational Speed & $n_{1}$ \\
Discharge Temperature of Compressor & $T_{2}$ \\
Discharge Pressure of Compressor & $P_{2}$ \\
Discharge Temperature of High Pressure Turbine & $T_{34}$ \\
Discharge pressure of High Pressure Turbine & $P_{34}$ \\
Compressor efficiency degradation & $D_{E C}$ \\
Compressor flow rate degradation & $D_{G C}$ \\
High pressure turbine efficiency degradation & $D_{E T}$ \\
High pressure turbine flow rate degradation & $D_{G T}$ \\
Power Turbine efficiency degradation & $D_{E P}$ \\
Power Turbine flow rate degradation & $D_{G P}$ \\
\hline
\end{tabular}

\subsection{Simulation Model Validation}

The dynamic simulation model is validated in this section. The start-up process is selected to show the maximum error of this model. All measurement parameters simulated by this model and tested by the overall performance test rig are compared, including high-pressure turbine rotational speed $n_{1}$, and high-pressure turbine discharge pressure.

The $P_{34}$ and compressor discharge temperature $T_{2}$, standing for the minimum, moderate and maximum simulation error, are cited as three examples. The comparative results are shown in Figures 6-8. The mean relative error of rotational speed is $0.5 \%$, and the mean relative error of compressor discharge temperature is $4.6 \%$. In conclusion, this model can predict the trend of measurement parameters, and the simulation error is under $4.6 \%$. It proves that this model can support fault diagnosis with transient data.

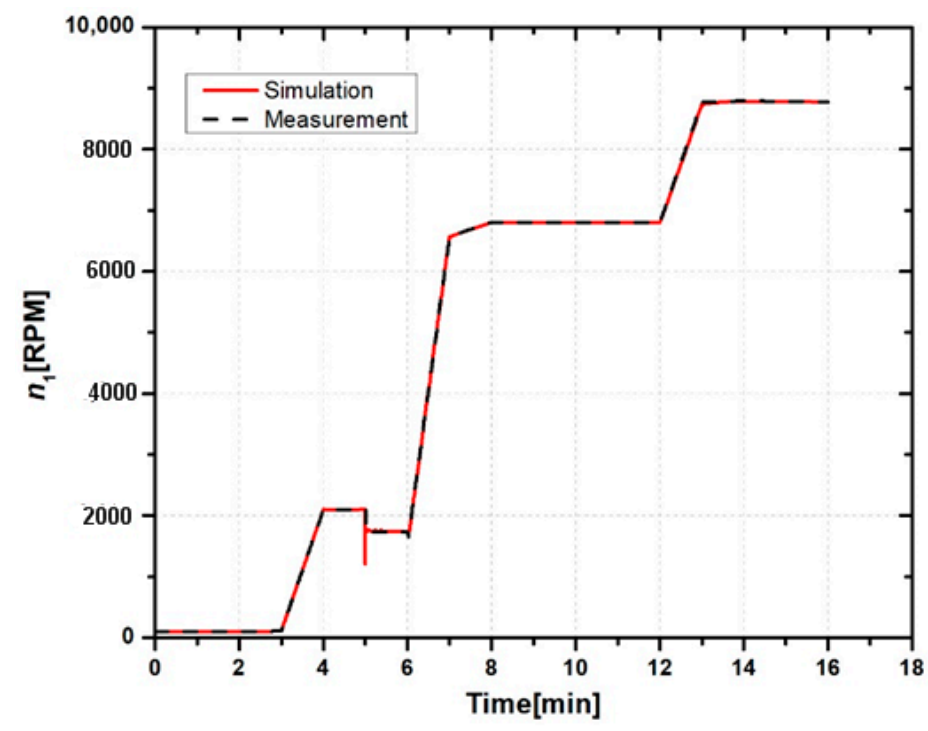

Figure 6. Comparison of simulation results and measuring data for high-pressure turbine rotational speed. 


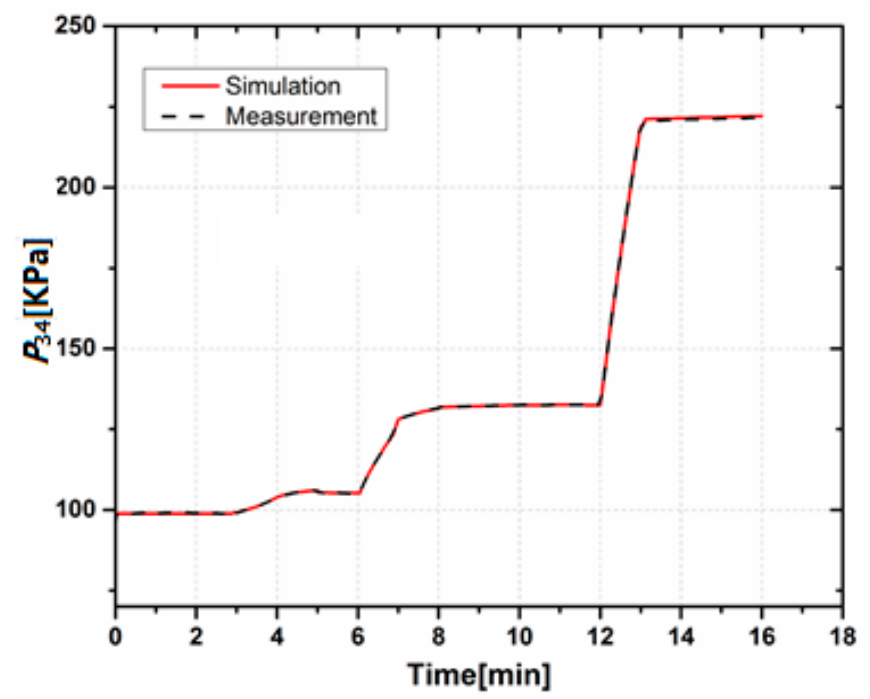

Figure 7. Comparison of simulation results and measuring data for high-pressure turbine discharge pressure.

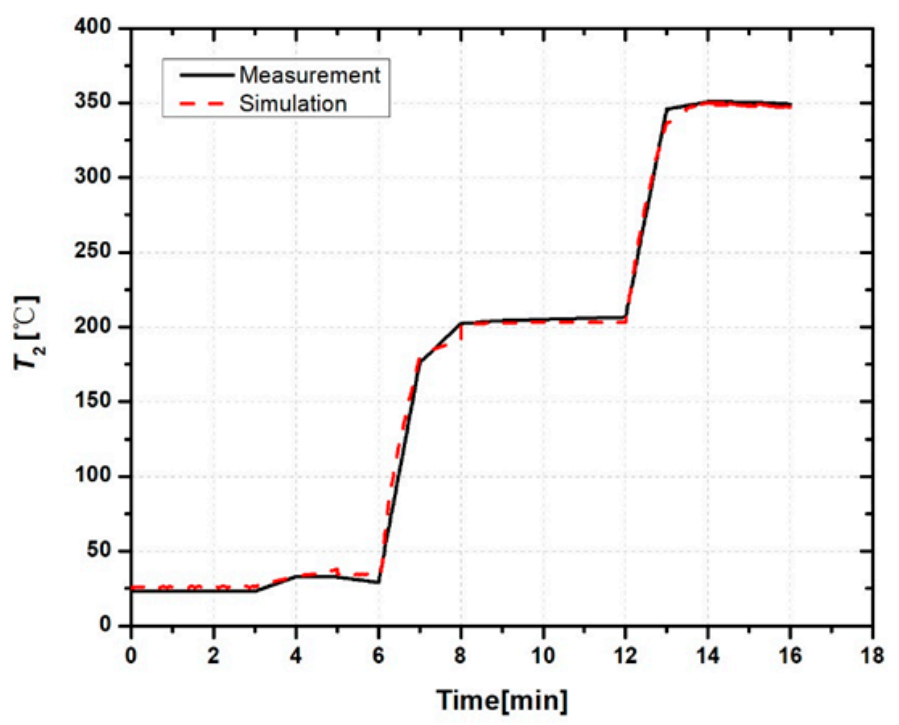

Figure 8. Comparison of simulation results and measuring data for compressor discharge temperature.

\subsection{Simulation with Component Degradation}

Compressor fouling is implanted in this section, to show the effect of gas path faults on the monitoring parameters. As the rule base of gas-path fault, flow rate degradation due to compressor fouling is three times the efficiency degradation [28]. The start-up process is studied, and the degradation of the compressor flow rate is assumed to be $3 \%$, the degradation of compressor efficiency is assumed to be $1 \%$. The simulation result of a healthy engine and deteriorated engine is listed in Figures 9 and 10.

It is obvious that the deviation between the monitoring parameters for healthy and deteriorated engines is small. For instance, this deviation of compressor discharge temperature is just $2-4{ }^{\circ} \mathrm{C}$ under $100 \%$ working conditions. It is easy to be annihilated by sensor noise. However, in the transient process, this deviation can be integrated. Figures 11 and 12 show the integrating result. Thus, the integrated deviation is selected as the object function for the cuckoo search algorithm. 


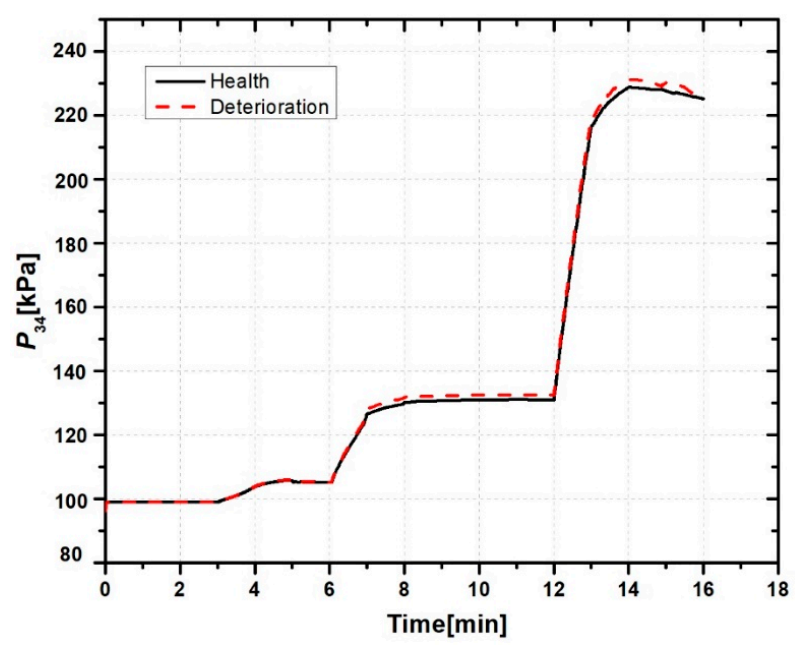

Figure 9. Simulation result of the high-pressure turbine discharge pressure.

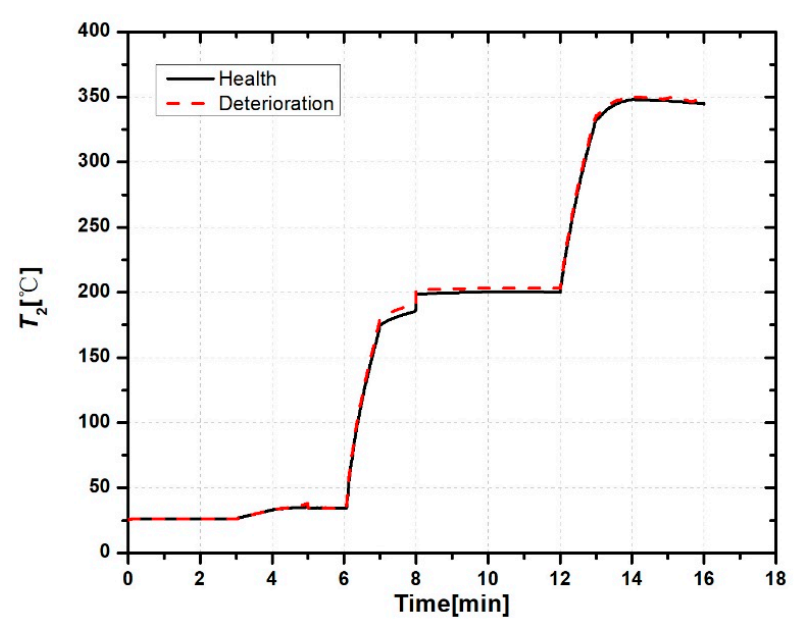

Figure 10. Simulation result of the compressor discharge temperature.

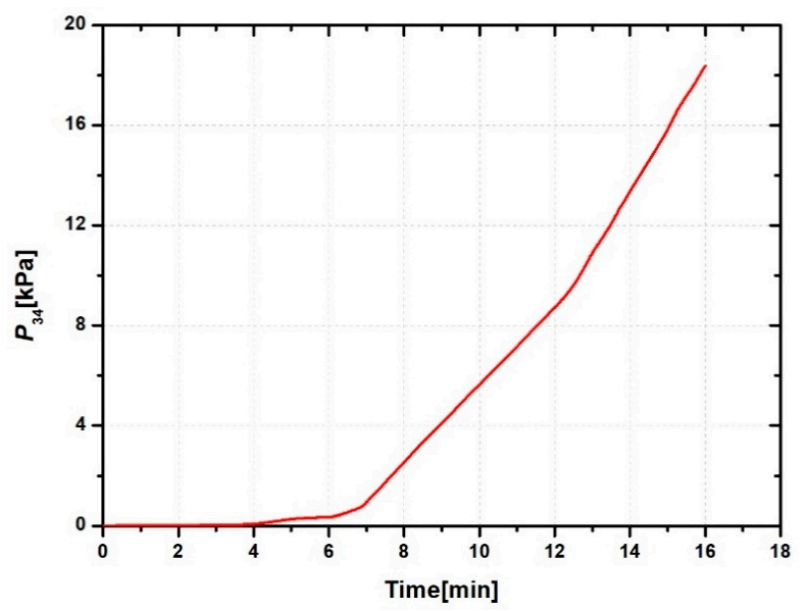

Figure 11. Integrating result of the high-pressure turbine discharge pressure. 


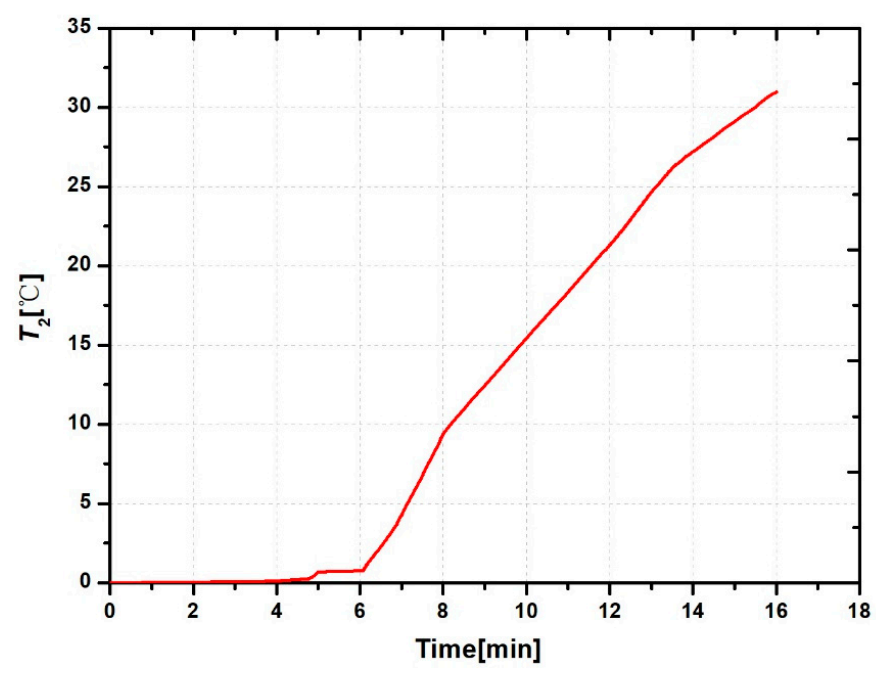

Figure 12. Integrating result of the compressor discharge temperature.

\subsection{Comparative Study}

The diagnostic results based on the steady-state data and transient data are compared in this section. Up to now, extensive research has been conducted to investigate the effects of physical faults on the performance of gas turbines. From the experimental results, the theoretical value of the ratio of the compressor flow rate degradation over the efficiency degradation is three [28-30]. This theoretical value was chosen as the criterion for the comparison of different diagnostic methods.

For comparison, two pieces of relatively stable steady-state data are selected for the same kind of fault diagnosis, as in Figure 13. They are the input for the steady-state diagnosis. The input for the transient process is the two complete pieces of data before and after washing.

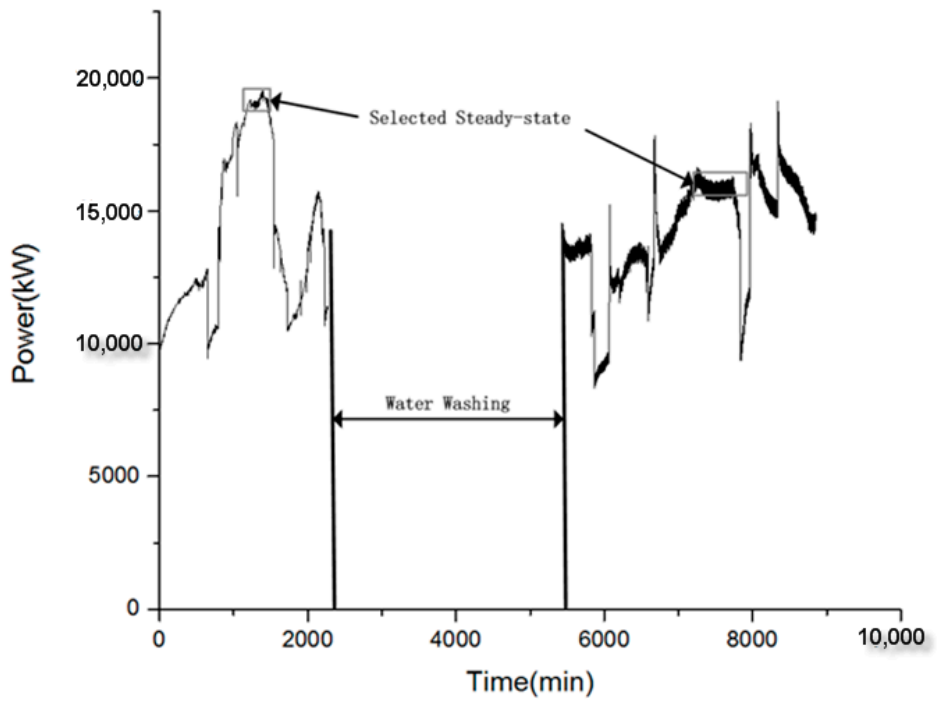

Figure 13. Selected working condition for diagnosis.

Component degradation is the relative value of the clean component. The improvement value of component degradation is selected for this comparative study. The diagnostic result of transient process analysis method is better than using steady state measurements, according to the result comparison, see Table 3. For convenience, diagnosis based on the steady-state is called Method A, and diagnosis based on the transient process is called Method B below. 
- The improvement of the compressor flow rate degradation is 13 times the value of its efficiency degradation based on Method A. It does not meet the theoretical value of three. The result of Method B is 1.96, closer to the theoretical value.

- These ratios for high pressure turbines are 3.86 and 5.33. It seems that Method A is more accurate than Method B for high-pressure turbines. Thus, the health condition of high-pressure turbines can be monitored by both Method A and Method B. However, washing decisions are usually made by compressor degradation. This means that Method B is more suitable for supporting maintenance scheduling.

- There is not any maintenance work being carried out for power turbines in this process. Therefore, the improvement of both its flow rate and efficiency should be zero, theoretically. This proves that Method B is more accurate for power turbine diagnosis.

Table 3. Comparison result of diagnostic results based on steady-state analysis and transient process analysis (\%).

\begin{tabular}{cccccccccc}
\hline Time & Process & $\boldsymbol{D}_{G C}$ & $\boldsymbol{D}_{E C}$ & $\boldsymbol{D}_{G C} / \boldsymbol{D}_{E C}$ & $\boldsymbol{D}_{G T}$ & $\boldsymbol{D}_{E T}$ & $\boldsymbol{D}_{G T} / \boldsymbol{D}_{E T}$ & $\boldsymbol{D}_{G P}$ & $\boldsymbol{D}_{E P}$ \\
\hline \multirow{2}{*}{ Before Washing } & Steady-state & 5.79 & 1.70 & - & 4.85 & 2.03 & - & 0.88 & 1.53 \\
& Transient process & 7.83 & 4.62 & - & 5.71 & 2.10 & - & 3.28 & 1.89 \\
\hline \multirow{2}{*}{ After Washing } & Steady-state & 2.02 & 1.48 & - & 2.03 & 1.30 & - & -0.17 & 1.07 \\
& Transient process & 1.54 & 1.41 & - & 2.56 & 1.42 & - & 2.95 & 1.76 \\
\hline \multirow{2}{*}{ Improvement } & Steady-state & 3.77 & 0.29 & 13.0 & 2.82 & 0.73 & 3.86 & 1.05 & 0.44 \\
& Transient process & 6.29 & 3.21 & 1.96 & 3.15 & 0.57 & 5.53 & 0.33 & 0.13 \\
\hline
\end{tabular}

\section{Conclusions}

In this paper, a gas turbine dynamic model was introduced to simulate its nonlinear dynamic behavior. The model was developed in the environment of Matlab/Simulink(MATLAB 2013a, The Mathworks, Inc., Natick, MA, USA). The start-up process was simulated via this model. The comparison of the simulation results to the field operating data showed the validity of the model and the advantage of using transient accumulated deviations. Some conclusions have been obtained as follows:

1. A new, non-linear, model-based diagnostic method, using gas turbine transient measurements and a cuckoo search (CS) algorithm, was tested to diagnose a gas turbine before and after a washing process.

2. Diagnosis with transient measurements is more relevant than diagnosis with steady-state measurements, when gas turbine faults contribute little to performance deviation in steady-state conditions or gas turbine output fluctuates greatly.

3. Gas turbine component fault diagnosis using transient data can be more effective than using steady state data, owing to magnifying fault signatures and extending the tracking time to eliminate variable uncertainties.

Acknowledgments: This study was co-supported by the National Natural Science Foundation of China (No. 51676182) and the National Natural Science Foundation of China (No. 51706132).

Author Contributions: De-tang Zeng and Dengii Zhou have proposed a research method based on fault diagnosis for transient performance of gas turbine, the simulation and experiment data are designed, analyzed and processed, and the manuscript is written. Chun-qing Tan has offered help for the simulations. Baoyang Jiang has proposed the resiving suggestions of manuscript.

Conflicts of Interest: The authors declare no conflict of interest. 


\section{Nomenclature}

$\pi \quad$ component pressure ratio

$\eta \quad$ component efficiency

$T_{1} \quad$ compressor inlet air temperature

$P_{1} \quad$ compressor inlet air pressure

$n_{1} \quad$ rotational speed of high pressure turbine

$Q_{c} \quad$ compressor inlet air mass flow

$\mathrm{T}_{2}$ compressor discharge air temperature

$\mathrm{P}_{2} \quad$ compressor discharge air pressure

$Q_{f} \quad$ fuel gas flow

$T_{3}$ high pressure turbine inlet temperature

$P_{3} \quad$ high pressure turbine inlet pressure

$T_{34}$ high pressure turbine discharge temperature

$P_{34}$ high pressure turbine discharge pressure

$Q_{t} \quad$ high pressure turbine mass flow

$T_{4} \quad$ power turbine discharge temperature

$P_{4} \quad$ power turbine discharge pressure

$Q_{p} \quad$ power turbine mass flow

$P_{c} \quad$ power consumption of compressor

$P_{t} \quad$ power generation of high pressure turbine

$P_{p} \quad$ power generation of power turbine

\section{References}

1. Kagermann, H.; Helbig, J.; Hellinger, A.; Wahlster, W. Recommendations for Implementing the Strategic Initiative INDUSTRIE 4.0: Securing the Future of German Manufacturing Industry. Final Report of the Industrie 4.0 Working Group. Available online: http:/ / forschungsunion.de/pdf/industrie_4_0_final_report. pdf (accessed on 16 January 2018).

2. Brynjolfsson, E.; McAfee, A. Race against the Machine: How the Digital Revolution is Accelerating Innovation, Driving Productivity, and Irreversibly Transforming Employment and the Economy; Digital Frontier Press: Lexington, MA, USA, 31 January 2012.

3. Isermann, R.; Ballé, P. Trends in the application of model-based fault detection and diagnosis of technical processes. Control Eng. Pract. 1997, 5, 709-719. [CrossRef]

4. Zhang, J. Multi-source remote sensing data fusion: Status and trends. Int. J. Image Data Fusion 2010, 1, 5-24. [CrossRef]

5. Lu, F.; Zheng, W.; Huang, J.; Feng, M. Life cycle performance estimation and in-flight health monitoring for gas turbine engine. J. Dyn. Syst. Meas. Control 2016, 138, 091009. [CrossRef]

6. Li, Y.G. Performance-analysis-based gas turbine diagnostics: A review. Proc. Inst. Mech. Eng. Part A J. Power Energy 2002, 216, 363-377. [CrossRef]

7. Sampath, S.; Gulati, A.; Singh, R. Fault diagnostics using genetic algorithm for advanced cycle gas turbine. In Proceedings of the ASME Turbo Expo 2002: Power for Land, Sea, and Air, Amsterdam, The Netherlands, 3-6 June 2002; American Society of Mechanical Engineers: New York, NY, USA, 2002; pp. 19-27.

8. Li, Y.G. A gas turbine diagnostic approach with transient measurements. Proc. Inst. Mech. Eng. Part A J. Power Energy 2003, 217, 169-177. [CrossRef]

9. Merrington, G.L. Fault Diagnosis of Gas Turbine Engine from Transient Data. J. Eng. Gas Turbine Power 1989, 111, 237-243. [CrossRef]

10. Merrington, G.L. Identification of dynamic characteristics for fault isolation purposes in a gas turbine using closed-loop measurements. In Proceedings of the Advisory Group for Aerospace Research and Development (AGARD) Conference, Quebec, QC, Canada, 30 May-3 June 1988; Volume 36, pp. 1-13.

11. Urban, L.A. Gas Turbine Engine Parameter Interrelationships; Hamilton Standard Division of United Aircraft Corporation: Hartford, Connecticut, 1969. 
12. Naderi, E.; Khorasani, K. Data-driven fault detection, isolation and estimation of aircraft gas turbine engine actuator and sensors. In Proceedings of the IEEE 30th Canadian Conference on Electrical and Computer Engineering (CCECE), Windsor, ON, Canada, 30 April-3 May 2017; pp. 1-6.

13. Meher-Homji, C.B.; Bhargarva, R. Condition Monitoring and Diagnostic Aspects of Gas Turbine Transient Response. Int. J. Turbo Jet-Engines 1994, 11, 99-111. [CrossRef]

14. Henry, J.R. CF-18/F404 transient performance trending. In Proceedings of the Advisory Group for Aerospace Research and Development (AGARD) Conference, Quebec, QC, Canada, 30 May-3 June 1988; Volume 37, pp. 1-13.

15. Merrington, G.; Kwon, O.K.; Goodwin, G.; Carlsson, B. Fault detection and diagnosis in gas turbines. J. Eng. Gas Turbines Power 1991, 113, 276-282. [CrossRef]

16. Simani, S.; Fantuzzi, C. Dynamic system identification and model-based fault diagnosis of an industrial gas turbine prototype. Mechatronics 2006, 16, 341-363. [CrossRef]

17. Simani, S.; Patton, R.J. Fault diagnosis of an industrial gas turbine prototype using a system identification approach. Control Eng. Pract. 2008, 16, 769-786. [CrossRef]

18. Lu, F.; Jiang, C.; Huang, J.; Wang, Y.; You, C. A novel data hierarchical fusion method for gas turbine engine performance fault diagnosis. Energies 2016, 9, 828. [CrossRef]

19. Kim, J.H.; Song, T.W.; Kim, T.S.; Ro, S.T. Model development and simulation of transient behavior of heavy duty gas turbines. J. Eng. Gas Turbines Power 2001, 123, 589-594. [CrossRef]

20. Schobeiri, M.T.; Attia, M.; Lippke, C. GETRAN: A generic, modularly structured computer code for simulation of dynamic behavior of aero-and power generation gas turbine engines. J. Eng. Gas Turbines Power 1994, 116, 483-494. [CrossRef]

21. Muir, D.E.; Saravanamuttoo, H.I.H.; Marshall, D.J. Health monitoring of variable geometry gas turbines for the Canadian Navy. J. Eng. Gas Turbines Power 1989, 111, 244-250. [CrossRef]

22. Blinstrub, J.; Li, Y.G.; Newby, M.; Zhou, Q.; Stigant, G.; Pilidis, P.; Hönen, H. Application of gas path analysis to compressor diagnosis of an industrial gas turbine using field data. In Proceedings of the ASME Turbo Expo 2014: Turbine Technical Conference and Exposition, Düsseldorf, Germany, 16-20 June 2014; American Society of Mechanical Engineers: New York, NY, USA, 2014; p. V03AT07A008.

23. Zhou, D.; Zhang, H.; Weng, S. A new gas path fault diagnostic method of gas turbine based on support vector machine. J. Eng. Gas Turbines Power 2015, 137, 102605. [CrossRef]

24. Yang, X.; Deb, S. Cuckoo search via L'evy flights. In Proceedings of the IEEE World Congress on Nature \& Biologically Inspired Computing. Piscataway, Coimbatore, India, 9-11 December 2009; pp. 210-214.

25. Civicioglu, P.; Besdok, E. A conceptual comparison of the Cuckoo-search, particle swarm optimization, differential evolution and artificial bee colony algorithms. Artif. Intell. Rev. 2011, 39, 315-346. [CrossRef]

26. Yang, X.S.; Deb, S. Engineering optimization by cuckoo search. Int. J. Math. Model. Numer. Optim. 2010, 1, 330-343.

27. Nguyen, T.T.; Vo, D.N.; Dinh, B.H. Cuckoo search algorithm for combined heat and power economic dispatch. Int. J. Electr. Power Energy Syst. 2016, 81, 204-214. [CrossRef]

28. Diakunchak, I.S. Performance deterioration in industrial gas turbines. J. Eng. Gas Turbines Power 1992, 114, 161-168. [CrossRef]

29. Joly, R.B.; Ogaji, S.O.T.; Singh, R.; Probert, S.D. Gas-turbine diagnostics using artificial neural-networks for a high bypass ratio military turbofan engine. Appl. Energy 2004, 78, 397-418. [CrossRef]

30. Mohammadi, E.; Montazeri-Gh, M. Simulation of full and part-load performance deterioration of industrial two-shaft gas turbine. J. Eng. Gas Turbines Power 2014, 136, 092602. [CrossRef]

(C) 2018 by the authors. Licensee MDPI, Basel, Switzerland. This article is an open access article distributed under the terms and conditions of the Creative Commons Attribution (CC BY) license (http:// creativecommons.org/licenses/by/4.0/). 